\title{
A possible case of etoricoxib induced fixed drug eruption
}

\author{
Apoorva $^{1}$, Girish K. ${ }^{1 *}$, Namritha C. Manjunath ${ }^{2}$
}

${ }^{1}$ Department of Pharmacology, ${ }^{2}$ Department of Dermatology and Venereology and Leprosy, Kempegowda Institute of Medical Sciences, Bangalore, Karnataka, India

Received: 21 November 2018 Accepted: 28 December 2018

*Correspondence to:

Dr. Girish K.,

Email: drgirish_k@

rediffmail.com

Copyright: (C) the author(s), publisher and licensee Medip Academy. This is an openaccess article distributed under the terms of the Creative Commons Attribution NonCommercial License, which permits unrestricted noncommercial use, distribution, and reproduction in any medium, provided the original work is properly cited.

\begin{abstract}
Fixed drug eruption (FDE) is a most commonly with adverse drug reaction seen with use of Non-steroidalanti-inflammatory drugs (NSAIDs) in particular nimesulide followed by antibiotics and anticonvulsants. Etoricoxib is a selective cyclo-oxygenase isoenzyme-2 inhibitor which is superior to conventional NSAIDs and causes less side effects. Authors present a case of fixed drug eruption due to etoricoxib in a male patient. A 50-year-old patient presented to Outpatient Department (OPD) of Dermatology of a Tertiary Care Hospital with complains of skin rashes over lips, oral cavity, trunk, both the upper and lower limbs, palm, soles, scrotum and glans penis since a week. The detailed history of the patient revealed the use of etoricoxib a week back, prescribed for low back pain. It was suspected that the cutaneous drug reaction was due to the use of etoricoxib. The suspected drug etoricoxib was stopped, patient was admitted and managed symptomatically. The above reaction was assessed to be "possible" as per WHO-UMC and Naranjo causality scale, "moderate" on Hartwig's scale and "Probably preventable" according to Schumock and Thornton criteria. This case reporting was done to sensitize the prescribers regarding rare side effects of the above drug and the need to confirm past history of drug reaction before prescription.
\end{abstract}

Keywords: Adverse drug reaction, Etoricoxib, Fixed drug eruptions, NSAIDs

\section{INTRODUCTION}

Etoricoxib is a commonly used NSAID, mainly for its analgesic effect in inflammatory conditions like arthritis, dental pain, gout and chronic back pain. Etoricoxib being a selective COX-2 inhibitor is becoming the first choice of analgesic among prescribers as they promote fast relief of pain and promote fewer gastrointestinal side effects like ulceration and gastrointestinal bleed which are seen with non-selective NSAIDs by blunting prostaglandins production.

Although its efficacy is well established, but side effects have not been explored till date in broader sense. Studies have shown various adverse effects due to etoricoxib like pretibial edema, thrombocytopenia and rashes. ${ }^{1}$ Few rare cases have been reported where etoricoxib has been seen to induce severe cutaneous drug eruption.

Fixed drug eruption is a commonly reported adverse drug reaction, where single or multiple round oedematous violaceous patch with well-defined borders and central bullous detachments. ${ }^{2-4}$ Lesions are seen to develop $48 \mathrm{hrs}$ after drug intake and are found to recur at the same site upon re-exposure to offending drug. ${ }^{2,5,6}$

In few cases they are often seen to resolve spontaneously with residual Hyperpigmented patches. ${ }^{2,5,6}$ Fixed drug eruption can be seen after administration of the drug for the first time or can be seen even after relapse. Although 
histopathological examination was not done in studied patient, the typical round patch supports the diagnosis of fixed drug eruption. Here authors report a case of fixed drug eruption following an intake of etoricoxib.

\section{CASE REPORT}

\section{History}

A 50-year-old male patient presented to OPD of Dermatology with a history of painful reddish lesion all over the body since a week.

Detailed history revealed that one week back the patient was prescribed Tab. etoricoxib $60 \mathrm{mg}$ by a local doctor for low back pain, after which he developed painful reddish lesions on the lips, oral cavity, trunk, both the upper and lower limbs, palm, soles, scrotum and glans penis.

It was associated with itching and burning sensation, difficulty in swallowing and pain in the oral cavity. There was no history of fever or photosensitivity. He also gave history of similar lesion in the past 4years following intake of analgesic.

\section{On examination}

Multiple hyperpigmented, erythematous to violaceous patches were present over face, neck, lips, upper and lower limbs, abdomen, palm, soles, scrotum and glans penis. Multiple ulcers of varying size and shape was present over buccal mucosa and hard plate (Figure 1 and 2).

\section{Investigations}

Routine investigations were normal except for mild leucocytosis.

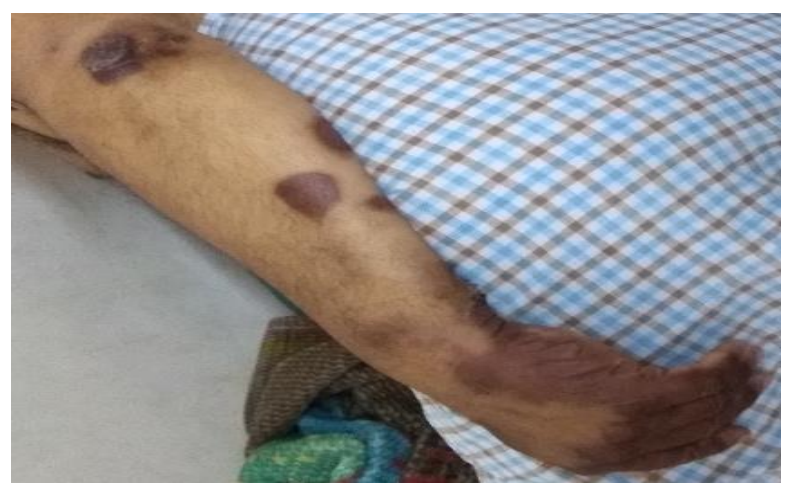

Figure 1: Fixed drug eruptions seen on hand.

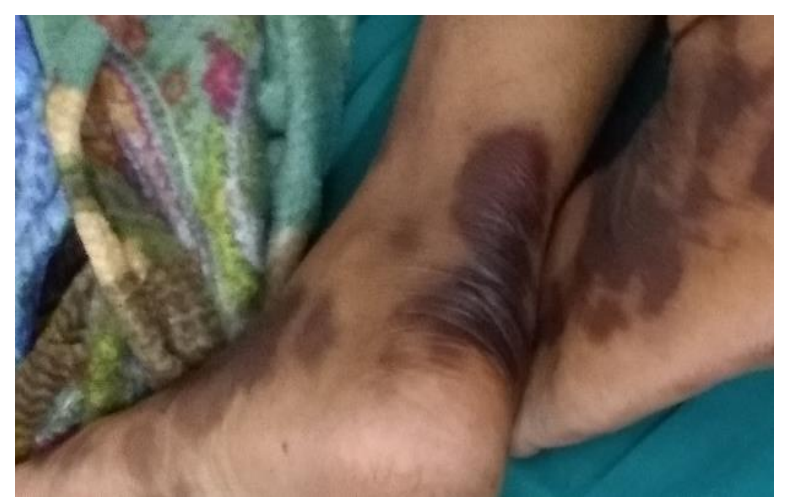

Figure 2: Fixed drug eruptions seen on feet.

Table 1: Naranjo adverse drug reaction probability scale. ${ }^{10}$

\begin{tabular}{|lllll|}
\hline Questions & Yes & No & Do not know & Score \\
\hline Are there previous conclusive reports on this reaction? & +1 & 0 & 0 & 1 \\
\hline $\begin{array}{l}\text { Did the adverse event appear after the suspected drug was } \\
\text { administered? }\end{array}$ & +2 & -1 & 0 & 2 \\
\hline $\begin{array}{l}\text { Did the adverse reaction improve when the drug was discontinued, or a } \\
\text { specific antagonist was administered? }\end{array}$ & +1 & 0 & 0 & 1 \\
\hline Did the adverse event reappear when the drug was re-administered? & +2 & -1 & 0 & 0 \\
\hline $\begin{array}{l}\text { Are there alternative causes (other than the drug) that could on their } \\
\text { own have caused the reaction? }\end{array}$ & -1 & +2 & 0 & -1 \\
\hline Did the reaction reappear when a placebo was given? & -1 & +1 & 0 \\
\hline $\begin{array}{l}\text { Was the drug detected in blood (or other fluids) in concentrations } \\
\text { known to be toxic? }\end{array}$ & +1 & 0 & 0 & 0 \\
\hline $\begin{array}{l}\text { Was the reaction more severe when the dose was increased or less } \\
\text { severe when the dose was decreased? }\end{array}$ & +1 & 0 & 0 \\
\hline $\begin{array}{l}\text { Did the patient have a similar reaction to the same or similar drugs in } \\
\text { any previous exposure? }\end{array}$ & +1 & 0 & 0 & 0 \\
\hline Was the adverse event confirmed by any objective evidence? & +1 & 0 & 0 \\
\hline Total score & & & 0 \\
\hline Interpretation: $\geq 9=$ Definite ADR; $5-8=$ Probable ADR; $1-4=$ Possible ADR; $0=$ Doubtful ADR & 0 \\
\hline
\end{tabular}




\section{Management}

Patient on admission was started on Intravenous Ceftriaxone, Intravenous Betamethasone and topical Fluticasone, antipruritic Hydroxyzine, Gentian violet for erosions over penis and hard palate.

\section{At the time of discharge}

Patient had significant reduction in lesions and erosions and was asked to review after 2 weeks to Dermatology OPD. Follow up after 2 weeks revealed that the lesions were healed.

\section{DISCUSSION}

The present study confirmed that NSAIDs are one of the most common medications which can cause fixed drug eruption. High usage of etoricoxib by prescription as well as self-administered routes has led to increase in reports of side effects and adverse reactions including dermatologic reactions.

There are various cutaneous adverse drug reactions reported following intake of etoricoxib ranging from erythema, angioedema, acute generalized exanthematous pustulosis and erythema multiforme like eruptions. ${ }^{2,7-9}$

Identification and discontinuation of offending drug helps in resolution of the lesions. No specific treatment is required; topical corticosteroids and oral antihistamincs may give symptomatic relief from itching.

The present case was subjected to causality assessment scale by Naranjo's criteria (Table 1) and WHO-UMC scale10.Assessment with Naranjo's scale indicated a total score of 4 indicating "a possible" causality relation between the drug and cutaneous reaction, when subjected to WHO-UMC scale -the causality assessment was possible.

The severity of ADR was assessed by Hartwig's severity assessment scale which pointed to level 4 severity indicating it to be "moderately severe" adverse drug reaction. The ADR was assessed to be "Probably preventable" according to Schumock and Thornton preventability scale.

Etoricoxib is an effective NSAID with minimal cutaneous adverse reaction but in doubtful circumstances, the possibility of any kind of adverse reaction to a drug must be kept in mind.

\section{CONCLUSION}

This case report suggests that monitoring of etoricoxib usage must be done to prevent the occurrence of ADR and prescribers must be aware of adverse effect that can be caused by it before initiating therapy.

Funding: No funding sources

Conflict of interest: None declared

Ethical approval: The study was approved by the Institutional Ethics committee of KIMS, Bangalore, India

\section{REFERENCES}

1. Kumar P. Etoricoxib-induced pretibial erythema and edema. Indian Dermatol Online J. 2015 Dec;6(Suppl 1):S47.

2. Antunes J, Prates S, Leiria-Pinto P. Fixed drug eruption due to etoricoxibe-A case report. Allergol Immunopathol (Madr). 2013.

3. Brahimi N, Routier E, Raison-Peyron N, Tronquoy AF, Pouget-Jasson C, Amarger S, et al. A three-yearanalysis of fixed drug eruptions in hospital settings in France. Eur J Dermatol. 2010 Jul 1;20(4):461-4.

4. Lee AY. Fixed drug eruptions. ixed drug eruptions. Incidence, recognition, and avoidance. Am J Clin Dermatol. 2000 Sep-Oct;1(5):277-85.

5. Shiohara T. Fixed drug eruption: pathogenesis and diagnostic tests. Curr Opin Allergy Clin Immunol. 2009 Aug 1;9(4):316-21.

6. Andrade P, Brinca A, Gonçalo M. Patch testing in fixed drug eruptions-a 20-year review. Contact Dermatitis. 2011 Oct;65(4):195-201.

7. Settipane GA. Aspirin and allergic diseases: a review. Am J Med. 1983 Jun 14;74(6):102-9.

8. Reginster JY, Malmstrom K, Mehta A, Bergman G, Ko AT, Curtis SP, Reicin AS. Evaluation of the efficacy and safety of etoricoxib compared with naproxen in two, 138-week randomised studies of patients with osteoarthritis. Ann Rheumatic Dis. 2007 Jul 1;66(7):945-51.

9. Mäkelä L, Lammintausta K. Etoricoxib-induced acute generalized exanthematous pustulosis. Acta dermatovenereologica. 2008 Jan 1;88(2):200-1.

10. Zaki S. Adverse drug reaction and causality assessment scales. Lung India. 2011 Apr 1;28(2):152.

Cite this article as: Apoorva, Girish K, Manjunath NC. A possible case of etoricoxib induced fixed drug eruption. Int J Basic Clin Pharmacol 2019;8:343-5. 